\title{
Citizenship beyond Irish and British
}

\author{
TOBIAS LOCK
}

\subsection{Introduction}

Protocol Article 3 provides that the UK and Ireland 'may continue to make arrangements between themselves relating to the movement of persons between their territories (the "Common Travel Area"), while fully respecting the rights of natural persons conferred by Union law'. We saw in Chapter 14 that the Common Travel Area (CTA) gives British and Irish citizens certain rights and privileges in each other's state; that a Memorandum of Understanding between the UK and Irish governments of 2019 reiterates its key features; and that the continued operation of the CTA constitutes a central plank of the policy behind the Protocol.

However, the CTA has only ever been a 'common' travel area for British and Irish citizens. ${ }^{1}$ The 'New (Northern) Irish', that is, persons resident on the island of Ireland who are not Irish or British citizens, are excluded from its benefits. This is no small group of people. According to estimates by Ireland's Central Statistics Office, in 2020 there were 644,400 non-Irish nationals living in Ireland out of a total population of 4.98 million (approximately 12.9 per cent). Of these, 116,900 were UK nationals and 344,000 (non-Irish) EU nationals. The remaining 183,500 were classed as coming from the 'rest of the world'. ${ }^{2}$ According to Oxford University's Migration Observatory, there were 53,867 non-UK or nonIrish citizens living in Northern Ireland in $2011 .^{3}$ Given an overall population of the island of Ireland of around 6.8 million, this means

1 The special status of Irish citizens in the UK and British citizens in Ireland is reflected in British nationality and Irish immigration law respectively; see B Ryan, 'The Common Travel Area between Britain and Ireland' (2001) 64 Modern Law Review 855, 859-62.

2 Central Statistics Office, Population and Migration Estimates, released 20 August 2020, www.cso.ie/en/releasesandpublications/er/pme/populationandmigrationestimatesa pril2020/.

3 Migration Observatory, Northern Ireland: Census Profile, 26 June 2014, https://migratio nobservatory.ox.ac.uk/resources/briefings/northern-ireland-census-profile/. 
that around 10 per cent of the population of the island can be categorized as New (Northern) Irish.

Many New (Northern) Irish enjoy EU citizenship rights either because they are EU citizens or because they enjoy derived rights as family members of EU citizens, that is, they enjoy the same rights as the EU citizen whom they are accompanying or joining. ${ }^{4}$ This meant that, until the end of the transition period on 31 December 2020, they were in a largely equivalent position in both Ireland and Northern Ireland to Irish and British citizens. ${ }^{5}$ In fact, except for the right to vote in national elections and the right to travel without carrying a passport, ${ }^{6} \mathrm{EU}$ citizenship rights went further than those granted by the CTA. Importantly, the CTA does not give rights to family members who are not British or Irish nationals. Furthermore, CTA rights are not directly effective or accompanied by anything like the primacy of EU law so that their enforceability hinges on their implementation in the domestic laws of the UK and Ireland. Additionally, British and Irish citizens resident in the other jurisdiction could rely on EU citizenship rights in addition to their rights under the CTA. Hence, during the UK's membership of the EU, EU citizenship rights bolstered the CTA rights of Irish and British citizens while giving EU nationals (almost) the same rights. The legacy of the UK's EU membership means that there is now a Byzantine web of rules determining who is entitled to cross the invisible and purportedly open border on the island and for what purpose, and who is not.

This chapter shows, however, that the situation has worsened for EU citizens and their third-country family members resident in both Ireland and Northern Ireland. Since the end of the Brexit transition period, many of these New (Northern) Irish are encountering new hurdles when crossing the Ireland-Northern Ireland border. This suggests that current CTA arrangements are unfit for the practical realities of life on the island of Ireland, where short-term visits to the other jurisdiction - social or work-related, to receive services or buy goods, or simply to transit

${ }^{4}$ According to Arts 6(2) and 7(2) of Directive 2004/38/EC of the European Parliament and of the Council of 29 April 2004 on the right of citizens of the Union and their family members to move and reside freely within the territory of the Member States [2004] OJ L157/77 (the Citizens' Rights Directive (CRD)).

${ }^{5}$ Citizens of Norway, Liechtenstein, Iceland (EEA citizens) and Switzerland and their family members enjoy similar rights. References to 'EU citizens' should be understood as including them mutatis mutandis.

6 The latter is not expressly guaranteed in the Memorandum of Understanding, but it is practised, except for persons arriving at Irish airports, where ID checks are carried out on anyone arriving. 
through the other jurisdiction in a car or on a public bus - are a daily occurrence for many and an occasional occurrence for most.

\subsection{EU Citizens Resident in Ireland}

The TCA does not contain a mobility chapter, as originally suggested by the EU. ${ }^{7}$ Hence, social visits by EU citizens resident in Ireland to Northern Ireland are subject to UK immigration rules. UK immigration rules currently class EU citizens as non-visa nationals who are permitted to visit the UK for up to six months. ${ }^{8}$ There are two main differences to the pre-Brexit situation. First, EU citizens no longer have a right to enter Northern Ireland; admission to Northern Ireland is now at the discretion of the UK authorities. This also means that refusal to admit EU citizens or their expulsion is based on UK law only. Second, EU citizens are now required to carry a valid passport when entering Northern Ireland, which is a change from the pre-Brexit situation when they were able to use their national ID card. ${ }^{9}$ This is particularly tricky in the context of crossings from Ireland to Northern Ireland as EU citizens residing in Ireland are entitled to enter Ireland - and subsequently reside there if the conditions of the Citizens' Rights Directive (CRD) are fulfilled ${ }^{10}$ - with a national ID card only.

EU citizens who reside in Ireland, but work in Northern Ireland, retain their status as frontier workers by virtue of Article 10 of the WA if they were frontier workers when the transition period ended. They retain their rights of entry and exit as before. ${ }^{11}$ However, frontier workers lose this status if they cease working in Northern Ireland, unless they become unemployed and continue to look for work there. ${ }^{12}$ By contrast to the situation before Brexit, those taking up frontier work after the end of the transition period now need to apply for a UK work visa to do so. The

${ }^{7}$ Draft text of the Agreement on the New Partnership with the United Kingdom, UKTF (2020) 14.

${ }^{8}$ UK Immigration Rules, Appendix: Visitor.

${ }^{9}$ It is difficult to estimate how many EU citizens are resident in Ireland relying only on their national ID card, but it is likely that there will be some. For instance, the German federal government revealed that in 2007 there were only about 28.2 million German passports in circulation, whereas Germany had a population of more than 80 million at the time, suggesting that many Germans only ever use an ID card to travel; Bundestag, DS $16 / 5507$.

${ }^{10}$ Arts 6 or 7 CRD (n 4).

11 Art 24(3) WA.

12 See Citizens' Rights (Frontier Workers) (EU Exit) Regulations 2020. 
same would be true for a former frontier worker, who may take up a position in Ireland and then may want to work in Northern Ireland again, since frontier workers' rights are not guaranteed for a prolonged period of time, as would be the case with permanent residence, which is only lost after five years of absence.

The situation is more complex where short-term business visits to Northern Ireland by EU citizens resident and working in Ireland are concerned. During the UK's EU membership, EU citizens had a right to enter Northern Ireland to work as self-employed or employed persons. They were also entitled to provide services either as a service provider in their own right or as posted workers, without much impediment. ${ }^{13}$ The lack of a mobility chapter in the TCA results in a substantial restriction of the possible activities that EU citizens resident in Ireland are permitted to undertake in Northern Ireland. It contains only basic provisions for the entry and temporary stay of EU and UK citizens for business purposes, which are reminiscent of those found in other EU free trade agreements, such as the EU-Canada Comprehensive Economic and Trade Agreement (CETA). ${ }^{14}$ Yet, as the following discussion shows, these temporary work visits are strictly circumscribed and thus in stark contrast to the free movement regime under EU law.

The TCA distinguishes five categories of persons entitled to stay temporarily in the UK: ${ }^{15}$

a) 'business visitors for establishment purposes', that is, where the EU citizen is posted to set up a subsidiary in Northern Ireland;

b) 'contractual service suppliers', that is, where an EU citizen - who must be employed by a legal person in Ireland - is posted to Northern Ireland to supply services to a final consumer under a contract not exceeding twelve months, but only if the EU citizen has worked for the legal person for at least one year prior and possesses at least three years' professional experience;

c) 'independent professionals', who may perform services in Northern Ireland only if they have six years' professional experience, and

13 See Art 56 TFEU and Directive 96/71/EC of the European Parliament and of the Council of 16 December 1996 concerning the posting of workers in the framework of the provision of services [1996] OJ L18/1.

14 EU-Canada Comprehensive Economic and Trade Agreement, Chapter 10, https://ec .europa.eu/trade/policy/in-focus/ceta/ceta-chapter-by-chapter/.

${ }^{15}$ Arts $140-43$ TCA. 
a university degree or equivalent qualification and the professional qualifications required in Northern Ireland to carry out the activity;

d) 'intra-corporate transferees', who must have worked for the legal person posting them for at least twelve months prior $^{16}$ and must be managers, specialists or trainee employees;

e) 'short-term business visitors', who are permitted only to attend meetings and consultations; conduct research and design; conduct marketing research; attend training seminars; attend trade fairs and exhibitions; engage in the sale or purchase of goods or services; perform after-sales or after-lease services; and oversee commercial transactions. ${ }^{17}$

The UK immigration rules list additional permitted activities that visitors are allowed to undertake. ${ }^{18}$

This does not, however, reflect the integrated nature of the economies of Ireland and Northern Ireland, where services are provided across the border on a daily basis. For instance, an EU citizen resident in Ireland working for a construction company in Ireland that carries out work in Northern Ireland may not qualify as a 'contractual service supplier' because they may not have the relevant three years' experience or they may not have worked for their employer for more than twelve months, or indeed the contract the employer is fulfilling may be for a duration of more than twelve months. Equally, an EU citizen working as a self-employed construction worker might not qualify as an 'independent professional' as they may not be considered a 'professional' with a university degree or equivalent qualification.

These restrictions on non-Irish EU citizens could turn out to be problematic for EU citizens seeking work in Ireland, given that no such restrictions on cross-border work are in place for Irish citizens employed by the same company. Hence, there is an incentive for employers that are active in the supply of cross-border services to employ Irish citizens rather than EU citizens. This causes frictions with Article 45 of the Treaty on the Functioning of the European Union (TFEU), which prohibits nationality discrimination of workers and which - at least as far as the discrimination angle is concerned - has horizontal direct effect, that is, it is binding on private employers. ${ }^{19}$

${ }^{16}$ Six months in the case of managers.

17 Annex 21 TCA.

${ }^{18}$ UK Immigration Rules Appendix Visitor: Permitted Activities, www.gov.uk/guidance/ immigration-rules/immigration-rules-appendix-visitor-permitted-activities.

19 Case C-281/98 Angonese ECLI:EU:C:2000:296; confirmed in Case C-94/07 Raccanelli ECLI:EU:C:2008:425. 


\subsection{EU Citizens in Northern Ireland}

The situation differs for EU citizens resident in Northern Ireland. As EU citizens they have a right to enter Ireland and stay there for up to three months without any further requirements. ${ }^{20}$ Hence, short-term visits for pleasure or for work are unproblematic. However, when performing work in Ireland they are not able to rely on the freedom to provide services provisions in Articles 56-62 TFEU as neither they (nor their employer) are normally 'established in a Member State other than that of the person for whom the services are intended'. They are thus solely reliant on their rights as EU citizens and the non-discrimination provision in Article 18 TFEU.

Their right of re-entry into Northern Ireland depends on their immigration status in the UK. If they arrived in the UK after 31 December 2020, this is determined by UK immigration law only. If they arrived before that date and have applied for either settled or pre-settled status, their right of re-entry is determined by the WA as well as (the partly more generous) UK immigration rules. They have a right to enter the UK and may do so with their national ID card up until 31 December $2025 .{ }^{21}$ After that they will need to be in possession of a passport.

If they have acquired permanent residence - or settled status in UK immigration law parlance - they may be absent from the UK for up to five years before losing that status. ${ }^{22}$ Hence, even extended work assignments in Ireland would not lead to a loss of status. The situation is different for those EU citizens who have not yet accumulated the necessary five years of residence in the UK in order to qualify for settled status. They are granted only pre-settled status, which they can lose in cases of prolonged absences. Continuity of residence is not affected by temporary absences of up to six months in any twelve-month period. ${ }^{23}$ Additionally, one temporary absence of up to twelve months is also permissible for important reasons, such as posting to another state.

\subsection{Third-Country Nationals Resident in Ireland}

Third-country nationals, that is, those who are neither EU citizens nor UK citizens, have always encountered immigration hurdles when crossing the

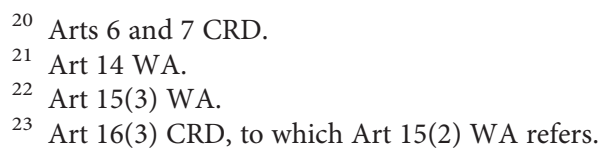


border on the island of Ireland. For those who have no family links to EU citizens, Brexit makes no difference. If resident in Ireland, they must comply with UK immigration law when entering Northern Ireland. The Short-Stay Visa Waiver Programme, which results in the mutual recognition between Ireland and the UK of certain short-stay visas issued to citizens of sixteen countries, does not have an equivalent for holders of long-term visas. Hence, a third-country national who is a resident of Ireland must apply for a UK visa before crossing the border to Northern Ireland, unless the third-country national is visa-exempt due to their citizenship.

For family members of EU citizens, by contrast, Brexit resulted in a worsening of their situation. The CRD grants family members of EU citizens certain privileges when accompanying or joining that EU citizen while travelling in the EU. They have a right to enter another member state, ${ }^{24}$ that is, up until the end of the transition period, they had a right to enter Northern Ireland. If they needed a visa, that visa had to be granted, that is, the UK had no discretion in that regard. ${ }^{25}$ If they were in possession of a residence card issued in accordance with the $\mathrm{CRD},{ }^{26}$ they were exempt from any visa requirements. ${ }^{27}$ This would typically be the case for family members of non-Irish EU citizens resident in Ireland as well as for family members of Irish citizens who had previously exercised their right to free movement and returned to Ireland. ${ }^{28}$ Additionally, while third-country family members of Irish citizens not in possession of a CRD-compliant residence card could be required to obtain a visa, that visa had to be issued as soon as possible and free of charge. ${ }^{29}$

No such rights exist for family members of EU citizens under the WA or the TCA. Equally, no provision is made for third-country national family members of Irish or British citizens in the Memorandum of

${ }^{24}$ Art 5(1) CRD.

${ }^{25}$ Case C-503/03 Commission v Spain ECLI:EU:C:2006:74, para 42.

26 Art 10 CRD.

27 This exemption applied to the UK despite its opt-out from Schengen; see Case C-202/13 McCarthy and Others ECLI:EU:C:2014:2450. It is (still) unclear whether this visa exemption applies only when the third-country national is accompanying or joining the EU citizen or also when they are travelling alone; see Elspeth Guild, Steve Peers and Jonathan Tomkin, The EU Citizenship Directive: A Commentary (2nd edn, Oxford University Press 2019) 107.

${ }^{28}$ Using the so-called Surinder Singh route, see Case C-370/90 Surinder Singh ECLI:EU: C:1992:296.

29 Art 5(2) CRD. See further Case C-459/99 MRAX ECLI:EU:C:2002:461, para 60. 
Understanding on the CTA, confirming that the CTA protects only British and Irish citizens. Hence, the rights of entry of third-country national family members for social visits to Northern Ireland are determined by UK immigration law only. Depending on their citizenship, they may be visa-exempt or they may have to apply for a short-term visa to visit Northern Ireland.

The TCA's provisions on short-term work visits apply only to 'natural persons of the other Party', ${ }^{30}$ which means that they must have the nationality of an EU member state. Again, this constitutes a worsening of the legal situation for third-country nationals lawfully resident in Ireland compared with the situation before Brexit took effect. According to the case law of the Court of Justice of the European Union (CJEU), the freedom to provide services covers the right to post workers who are third-country nationals to another member state without the need to apply for a work permit for these workers. ${ }^{31}$ This option now no longer exists, unless each third-country national obtains the relevant UK visa.

Family members receive a brief mention in the TCA in the context of intra-corporate transferees, ${ }^{32}$ obliging both the EU and the UK to allow their entry and temporary stay, but these commitments do not have direct effect and need to be implemented by the parties to the TCA first. Again, this constitutes a reduction in rights as previously they would have been entitled to accompany their EU citizen family member as a matter of a directly effective right.

\subsection{Third-Country Nationals Resident in Northern Ireland}

Ireland is the only EU member state not bound by Regulation 2018/1806 listing the third countries whose nationals must be in possession of visas. Hence, Irish immigration law autonomously determines the thirdcountry nationals who are visa-exempt and those who must be in possession of a visa. As mentioned previously, there is no parallel programme for long-term residents to the Short-Stay Visa Waiver Programme operated jointly by the UK and Ireland.

30 Arts 140-45 TCA.

31 Case C-43/93 Vander Elst ECLI:EU:C:1994:310. It is therefore not surprising that Directive 96/71/EC of the European Parliament and of the Council of 16 December 1996 concerning the posting of workers in the framework of the provision of services [1996] OJ L18/1 is not limited to the posting of EU citizens.

32 Annex 23 TCA. 
Hence, third-country nationals resident in Northern Ireland, who are not visa exempt, may apply for a so-called 'short stay C-visa', which is valid for ninety days, but only for a single entry into Ireland. For most permanent residents of Northern Ireland, a multi-journey visa, which allows for multiple entries into Ireland, is therefore the better option. This may be issued for a period of up to five years. Certain nationalities are exempt from having to pay the visa fee for this type of visa. However, as with most visa applications, the applicant has no right to be issued either visa.

If the third-country national is a family member of a (non-Irish) EU citizen, they have a right to enter Ireland if they are accompanying the EU national or joining them. ${ }^{33}$ They do not have that right when travelling alone and must - unless exempt due to their nationality - apply for a visa before crossing the border. The WA stipulates that family members of EU nationals resident in the UK continue to enjoy their rights as family members. This means in particular that they may acquire a right of permanent residence after five years of continuous residence as a family member. ${ }^{34}$ By contrast with the legal situation before the end of the transition period, they are no longer issued with a CRD-compliant residence card; ${ }^{35}$ instead, they are given an 'EU Settlement Scheme Residence Card' (EUSS Residence Card), which entitles them to enter the UK. However, much like the EU/EEA (European Economic Area) residence card, that does not entitle them to travel visa-free within the EU when not accompanying or joining an EU citizen. Additionally, they may be required to obtain a visa for entering Ireland even if in possession of an EUSS Residence Card and accompanying their family member. ${ }^{36}$ By contrast to other third-country nationals, however, they have a right to be granted a visa when accompanying or joining their EU citizen family member and that visa has to be granted for free.

The situation is more difficult where family members of Irish nationals who are resident in Northern Ireland are concerned. ${ }^{37}$ The beneficiaries of EU citizenship law are those 'Union citizens who move to or reside in a Member State other than that of which they are a national. ${ }^{38}$ Since the $\mathrm{UK}$ is no longer a member state, EU citizenship law no longer applies to Irish citizens in Northern Ireland. Hence, the family member of an Irish citizen resident in Northern Ireland accompanying them on a trip to

${ }^{33}$ Art 5 CRD.

${ }^{34}$ Art 15 WA.

${ }^{35}$ Under Art 10 CRD.

36 The card does not entitle them to the right contained in Art 5(2) CRD.

37 On this in more detail see Chapter 15.

38 Art 3 CRD. 
Ireland is not entitled to right of entry under the CRD. Hence, entry of family members of Irish citizens from Northern Ireland to Ireland is determined by Irish law only. The same goes for family members of British nationals in Northern Ireland given that they are no longer classed as family members of an EU citizen when entering Ireland.

\subsection{Conclusion}

By granting free movement rights only to Irish and British citizens, the CTA falls short of its own ambition of being a 'common' travel area on the island of Ireland. While the exclusion of the growing cohort of New (Northern) Irish is not in itself a new development, the consequences of Brexit mean that the number of those for whom short-term visits across the border on the island of Ireland have become more difficult, or indeed impossible in some cases, has grown considerably in that it now includes EU citizens and their family members.

The CTA's blindness towards family members - while historically explicable due to the very low numbers of non-British or Irish citizens resident on the island of Ireland in $1922^{39}$ - is particularly remarkable. The CJEU has long recognized that obstacles to the movement of family members constitute obstacles to the movement of those entitled to move. ${ }^{40}$

The limitations of the CTA are particularly evident on the island of Ireland, which contains the only international land border within the CTA. The post-Brexit restrictions on the ability of New (Northern) Irish to cross that border show that the arrangements in the Protocol and the CTA do not retain the status quo. The border may continue to appear open, but for an increasing number of New (Northern) Irish it is not. The consequences are not confined to inconveniences, such as not being able to go on shopping trips across the border; they are potentially much further reaching and contradict broader EU law aspirations of nondiscrimination. Employers engaged in cross-border trade in Ireland may well decide not to hire EU citizens if they fear that those EU citizens cannot lawfully provide services in Northern Ireland.

39 Ryan (n 1) 871-74.

40 Starting with Surinder Singh (n 28); expanded upon in Case C-60/00 Carpenter ECLI:EU: C:2002:434, para 38; MRAX, para 53; Commission $v$ Spain (n 25) para 41; the preamble of the CRD considers the extension of the right of free movement to family members of EU citizens a corollary of its exercise in 'freedom and dignity'. 
